\title{
Biological control of Echinothrips americanus by phytoseiid predatory mites and the effect of pollen as supplemental food
}

\author{
Somayyeh Ghasemzadeh ${ }^{1,2} \cdot$ Ada Leman $^{1} \cdot$ Gerben J. Messelink $^{1}$ (D)
}

Received: 5 January 2017/ Accepted: 9 November 2017/Published online: 11 November 2017

(C) The Author(s) 2017. This article is an open access publication

\begin{abstract}
The poinsettia thrips, Echinothrips americanus Morgan, is an upcoming pest in greenhouse crops, causing serious damage in various vegetable and ornamental crops through extensive foliage feeding. We assessed which stages of E. americanus are attacked and killed by the phytoseiid predatory mites Amblyseius swirskii (Athias-Henriot), Amblydromalus limonicus (Garman and McGregor), Euseius gallicus Kreiter and Tixier and Euseius ovalis (Evans). Both the predation and oviposition rates were assessed in the laboratory to evaluate which mite species is potentially the most effective predator of $E$. americanus. In two greenhouse trials with non-flowering sweet pepper plants, we compared the efficacy of the predators E. gallicus and E. ovalis with A. swirskii and we assessed how this was affected by the application of cattail pollen. All stages of $E$. americanus, except adults, were consumed by all species of predatory mites. The highest predation and oviposition rates were recorded for A. limonicus followed by A. swirskii and E. ovalis when first and second larval stages were provided as prey, but E. ovalis appeared to be the best predator of thrips pupae. Euseius gallicus displayed very low predation and oviposition rates compared to the other species of predatory mites. Cattail pollen did not support the population growth of poinsettia thrips, but it strongly increased the predatory mite population densities, particularly those of E. ovalis. Both A. swirskii and E. ovalis significantly reduced thrips densities on plants. The application of pollen significantly enhanced the control of E. americanus by A. swirskii; this was not the case for E. ovalis. Euseius gallicus did not reduce densities of E. americanus on sweet pepper plants, not even at high densities in the presence of pollen.
\end{abstract}

Keywords Amblyseius swirskii · Amblydromalus limonicus · Euseius ovalis · Euseius gallicus $\cdot$ Greenhouse

Gerben J. Messelink

gerben.messelink@wur.nl

Wageningen UR Greenhouse Horticulture, PO Box 20, 2265 ZG Bleiswijk, The Netherlands

2 Department of Plant Protection, Faculty of Agriculture, University of Urmia, Pardas-e Nazlou, 11th $\mathrm{km}$ of Serow Road, Urmia, Iran 


\section{Introduction}

Many species of thrips (Thysanoptera) are pests of economic importance in agricultural crops (Heinz et al. 2004; Lewis 1997; Mound 2005). The most important species in greenhouse crops are western flower thrips, Frankliniella occidentalis (Pergande), tobacco thrips, Thrips tabaci (Lindeman), melon thrips, Thrips palmi Karny, and chilli thrips, Scirtothrips dorsalis Hood, which are all highly polyphagous and damage various ornamental and vegetable greenhouse crops (Heinz et al. 2004; Lewis 1997; Oetting et al. 1993). A relatively new pest in greenhouse crops is the poinsettia thrips, Echinothrips americanus Morgan. This thrips species is native to eastern North America (Oetting 1987), but it has spread rapidly across Europe since 1995 (Vierbergen et al. 2006) and more recently, it also established in China ( $\mathrm{Li}$ et al. 2014). The poinsettia thrips is also highly polyphagous and causes serious damage in various vegetable and ornamental crops through extensive foliage feeding (Ramakers et al. 2000; Varga et al. 2010; Vierbergen et al. 2006).

In general, control of thrips with phytoseiid predatory mites has proven to be very successful (Gerson and Weintraub 2007), and was shown for western flower thrips (Messelink et al. 2006; van Houten et al. 1995), tobacco thrips (Ramakers 1980), melon thrips (Kakkar et al. 2016) and chilli thrips (Arthurs et al. 2009). However, biological control of E. americanus by predatory mites has not received much attention and the few studies done indicate that predatory mites are not very effective (Hoogerbrugge et al. 2014; Opit et al. 1997). Up to now, it is unknown which stages of E. americanus are vulnerable to predation by phytoseiid predatory mites.

In this study we assessed which stages of E. americanus are attacked and killed by four species of phytoseiid predatory mites: (1) Amblyseius swirskii (Athias-Henriot) and (2) Amblydromalus limonicus (Garman and McGregor), both commercially available and effective predators of western flower thrips (Knapp et al. 2013; Messelink et al. 2006), (3) Euseius gallicus Kreiter and Tixier, recently commercialised and promoted to control thrips in roses in combination with pollen application (Pijnakker et al. 2014; Put et al. 2016) and (4) Euseius ovalis (Evans), an effective predator of western flower thrips and whiteflies (Messelink et al. 2008). Both the predation and oviposition rates of the predatory mites were assessed in the laboratory to evaluate which mite species is potentially the most effective predator of E. americanus. However, not only these factors are important for the selection of efficient predators, but also how well the predators develop on alternative food sources that are used to conserve predator populations in greenhouses (Messelink et al. 2014). Several studies showed that adding pollen to a crop can enhance pest control by predatory mites (Adar et al. 2014; Delisle et al. 2015; Duarte et al. 2015; Leman and Messelink 2015; Nomikou et al. 2010; van Rijn et al. 2002) and this was recently validated in commercial greenhouse crops such as roses (Put et al. 2016). Therefore, we evaluated how the control of E. americanus is affected by the application of pollen as supplemental food for the predatory mites.

When pollen is applied as supplemental food for predatory mites, there is a potential risk of promoting pollen-feeding thrips under certain conditions, as pollen is also edible for this thrips (Hulshof et al. 2003; Leman and Messelink 2015; van Rijn et al. 2002; Vangansbeke et al. 2016). Because E. americanus is a leaf-dwelling thrips species, it is not expected to feed on pollen. The application of pollen as supplemental food for predatory mites may thus pose less risk in the presence of $E$. americanus than with western flower thrips. However, pollen may distract predatory mites from preying on E. americanus, as was shown for Neoseiulus cucumeris (Oudemans) when preying upon western flower thrips (Skirvin et al. 2007), and this may particularly be true when E. americanus is not the preferred prey of predatory mites. We hypothesized that the effect of pollen on the control 
of E. americanus by predatory mites depends on the species of predatory mite. Species with a strong preference for pollen could potentially feed more on pollen than on the pest than species with a less strong preference. However, such short-term effects can be compensated by increased predator populations (Sabelis and van Rijn 2005) and the predatory mite that shows the highest developmental rate on pollen may therefore eventually also give the best control of thrips. Even predatory mites that show low predation rates of E. americanus in the laboratory may be effective when applied in combination with pollen that promotes their population growth. In this study, we compared the control of E. americanus on plants by A. swirskii (Athias-Henriot), the most commonly used predatory mite for thrips control, with E. ovalis and E. gallicus, two species that perform well on pollen. In addition, we included treatments to assess the direct effects of pollen on E. americanus and predatory mite densities.

\section{Materials and methods}

\section{Cultures of predatory mites and Echinothrips}

The predatory mites A. swirskii and A. limonicus were obtained from Koppert biological systems (Berkel en Rodenrijs, The Netherlands) and further reared on a diet of cattail pollen (Typha latifolia). This pollen was collected in The Netherlands, dried and stored at $-20{ }^{\circ} \mathrm{C}$ for 1 year. Amblyseius swirskii was reared on plastic arenas $(6 \times 12 \mathrm{~cm})$ placed on a wet sponge with a layer of cotton on the top in plastic trays with water. Strips of wet filter paper were placed along the sides of arena to provide the mites with water (according to van Rijn and Tanigoshi 1999). The same method was used for A. limonicus, except that the plastic arenas were replaced by sweet pepper leaves, placed upside down on water-saturated cotton wool. This mite probably needs to feed on plant tissue in addition to pollen (Messelink et al. 2006). The predatory mite E. gallicus was originally collected in 2012 from greenhouse roses in the Netherlands, where it occurred naturally. Euseius ovalis was originally collected in 1998 from a cucumber crop in Taiwan. Both species were reared since then on sweet pepper leaves and cattail pollen as described above. The predatory mites cultures were placed in climate rooms with $16 \mathrm{~h}$ of artificial illumination per day, at $25{ }^{\circ} \mathrm{C}$ and $70 \%$ relative humidity (RH).

Poinsettia thrips E. americanus were reared on sweet pepper plants cv Spider in a small greenhouse unit. In order to produce thrips stages of the same age for the laboratory experiment, adult thrips (approximately 30 females) were collected from this culture and added to sweet pepper leaf discs placed upside down on water agar in 280-ml plastic boxes $(\varnothing 8 \mathrm{~cm} \times 5 \mathrm{~cm})$ (Paardekooper Verpakkingen, Oud-Beijerland, The Netherlands). Ventilation was possible through a hole in the lid covered with insect gauze (mesh size $80 \mu \mathrm{m}$ ). After $24 \mathrm{~h}$, the adult thrips were removed and the larvae that emerged from the eggs were kept on the same leaf discs until they reached the stage needed for the experiment. Thrips were reared under the same climatic conditions as the predatory mites.

\section{Predation and oviposition rates by predatory mites on Echinothrips americanus stages}

The daily consumption of E. americanus stages by female predatory mites and the corresponding oviposition rates were assessed in the laboratory. Oviposition rates of phytoseiid mites are known to be a good stand-in parameter for population growth rates (Janssen 
and Sabelis 1992) and we therefore measured it. The experiment was conducted in 30-ml transparent plastic medicine cups $(\varnothing 2.5 \mathrm{~cm}$ at the bottom and $4 \mathrm{~cm}$ high) (Vandeputte Medical Nederland, Nieuwegein, The Netherlands) with a sweet pepper leaf disc (cv Maranello, Ø $2.5 \mathrm{~cm}$; Enza Zaden, The Netherlands) placed with the abaxial side up in water agar. Ventilation was possible through a hole in the lid covered with insect gauze (mesh size $80 \mu \mathrm{m}$ ). Each cup was provided with 10 individuals of E. americanus of either first instars, second instars, pupae or adults, which were all gently transferred with a tiny brush from the boxes with sweet pepper leaves in which they were reared. After adding the thrips, each cup was provided with one young female predatory mite of the species $A$. swirskii, A. limonicus, E. ovalis or E. gallicus and the cups were placed in a climate chamber at $25{ }^{\circ} \mathrm{C}, 70 \% \mathrm{RH}$ and a $16: 8 \mathrm{~L} / \mathrm{D}$ regime. Predatory mites were at the beginning of their oviposition period. The predatory mites were transferred to a new cup with again 10 new thrips individuals of the same stage every $24 \mathrm{~h}$ for 3 days in a row. The daily predation and oviposition rates were assessed directly after removal of the predators under a stereomicroscope. Thrips predation was recognized by the presence of bodies that were sucked empty. Each predatory mite-thrips stage combination was repeated 6 times. The daily predation rate was calculated by taking the mean of the 3 days of measurement. The mean daily oviposition rate of the predatory mites was based on the measurement of day 2 and 3. Data of the first day were omitted to exclude the effect of the previous food source of the predatory mites (Sabelis 1990).

\section{Effect of pollen on predation rates}

A separate laboratory experiment was carried out to assess the effects of pollen on thrips predation by the predatory mites $A$. swirskii and E. ovalis. We selected these predatory mite species because they showed similar predation rates in the previous trial, but their preference for pollen feeding might differ from each other. The same method was used as described above. The leaf discs in the cups were provided with either eight first instars of E. americanus, $4 \mathrm{mg}$ cattail pollen (similar source as above) or the combination of eight thrips larvae and $4 \mathrm{mg}$ cattail pollen. Each treatment was repeated 6 times and the cups were again placed in a climate chamber at $25{ }^{\circ} \mathrm{C}, 70 \% \mathrm{RH}$ and a 16:8 L/D regime. Thrips predation was measured daily for 3 days as above.

\section{Greenhouse trial with Amblyseius swirskii and Euseius gallicus on sweet pepper}

A greenhouse trial was conducted to assess the capacity of the two predatory mite species A. swirskii and E. gallicus to control E. americanus on sweet pepper plants and the effects of the presence of cattail pollen as a supplemental food source. Although E. gallicus did not perform well in the laboratory trial, we included this species to see if the application of pollen could enhance control, knowing that this species develops well on pollen. The pollen in this experiment was obtained from Biobest (Nutrimite ${ }^{\mathrm{TM}}$, Westerlo, Belgium). The experiment was carried out in April-May in a greenhouse compartment of $24 \mathrm{~m}^{2}$ with three tables of $9 \mathrm{~m}^{2}$ each at Wageningen UR Greenhouse Horticulture in Bleiswijk, the Netherlands. The experimental unit consisted of a 6-1 pot (36 cm diameter) filled with peat and a 9-week-old sweet pepper plant (cv. Maranello; Enza Zaden, The Netherlands). To prevent the production of pollen (which would interfere with pollen application as a treatment), we removed all flower buds at the beginning of the trial and this was done throughout the experiment every week. Each sweet pepper plant was subsequently 
enclosed in a mesh cage $(35 \times 35 \times 60 \mathrm{~cm})$ made of fine gauze (mesh size $500 \mu \mathrm{m})$ (Vermandel, Hulst, The Netherlands). Nutrients for the plants were provided through drip irrigation for $10 \mathrm{~min}$ per day. The following treatments were compared: (1) E. americanus, (2) E. americanus + pollen, (3) E. americanus + A. swirskii, (4) E. americanus + E. gallicus, (5) A. swirskii + pollen, (6) E. gallicus + pollen, (7) E. americanus $+A$. swirskii + pollen and (8) E. americanus + E. gallicus + pollen. The experiment was setup as a randomized block design with six blocks which were distributed over three tables, thus in total 48 cages. Plants in treatments with E. americanus were infested with 10 adults of $E$. americanus each, which was repeated after 1 week. Predatory mites were released once on the same day as the second thrips release. For this release, we selected female predatory mites which, using a small brush, were collected and placed on a leaf disc of sweet pepper ( $4 \mathrm{~cm}$ diameter). Ten female predatory mites were released per plant by placing the leaf discs on the sweet pepper plants. The pollen was added shortly after the releases of the predatory mites by dusting $0.013 \mathrm{~g}$ per plant using a small brush and this was repeated after 2 weeks. Densities of thrips and predatory mites were assessed once, 3 weeks after the introduction of the predatory mites by counting all predators and thrips per plants. For practical reasons, population dynamics were not followed longer, because the plants did not fit anymore in the cages. All leaves were cut and transported to the laboratory in closed plastic bags for assessments under a binocular microscope $(40 \times$ magnification). Twenty female predatory mites per plant were mounted in temporary preparations and species were identified under a microscope to check for contaminations. Temperature and relative humidity in the greenhouse compartment were recorded every 5 min using a climate recorder (Hoogendoorn Growth Management, Vlaardingen, The Netherlands) throughout the experiment. The average temperature and relative humidity during the experiment were $24.2^{\circ} \mathrm{C}$ (range $22.1-26.8{ }^{\circ} \mathrm{C}$ ) and $66 \%$ (range 60-75\%), respectively. One replicate of the treatment with pollen and $E$. americanus became infected with predatory mites (both E. gallicus and A. swirskii) and this replicate was omitted from further analyses.

\section{Greenhouse trial with Amblyseius swirskii and Euseius ovalis on sweet pepper}

The set-up of this second greenhouse trial was similar to first trial, but now E. gallicus was replaced by E. ovalis. We decided to select this species and not $A$. limonicus because we wanted to compare the impact of pollen on the control of E. americanus between the most commonly used species $A$. swirskii and a species that develops faster on pollen. This trial was executed in July, which resulted in slightly higher temperatures and lower humidity levels than in the first trial. The average temperature and relative humidity during the experiment were $26.1{ }^{\circ} \mathrm{C}$ (range $25.9-30.6{ }^{\circ} \mathrm{C}$ ) and 60\% (range 47-69\%), respectively. Four plants without released predatory mites became infected by predatory mites (mainly E. ovalis): 3 replicates of the treatment with pollen and E. americanus and one of the treatment with only E. americanus. These replicates were omitted from further analyses.

\section{Statistical analysis}

Predation rate data were square root transformed and oviposition rate data $\log (+1)$ transformed to adjust the data for homogeneity of variance and normality, followed by a two-way ANOVA, with predator species and thrips stage as factors. Differences among predatory mite species were analysed by Fisher's least significant difference (LSD) post hoc tests $(\alpha=0.05)$. The same analysis was done with the data of the two greenhouse trials: 
a two-way ANOVA with predator and food as factors was performed with the $\log (\mathrm{x}+1)$ transformed densities of thrips and predatory mites, followed by Fisher's LSD post hoc tests $(\alpha=0.05)$. All statistical analyses were performed using the statistical package GenStat, Release 18.1.

\section{Results}

\section{Predation and oviposition rates by predatory mites on Echinothrips americanus stages}

The interaction between the factors predator species and thrips stage was significant both for predation $\left(\mathrm{F}_{6,239}=9.51, p<0.001\right)$ and oviposition rates $\left(\mathrm{F}_{6,239}=2.43, p=0.027\right)$. The highest predation rates were found for A. limonicus, followed by E. ovalis and $A$. swirskii for first and second instars of thrips, but thrips pupae were mostly consumed by $E$. ovalis (Fig. 1a). Predation rates were the lowest for E. gallicus for all thrips stages (Fig. 1a). The highest oviposition rates on a diet of first or second thrips instars were found for A. limonicus, but oviposition did not differ from A. swirskii and E. ovalis on a diet of

Fig. 1 Predation (a) and oviposition (b) rates of young adult females of Amblydromalus limonicus, Amblyseius swirskii, Euseius ovalis and Euseius gallicus on first larval (L1), second larval (L2) and pupal stages of Echinothrips americanus on sweet pepper leaf discs. Shown are the daily mean numbers of consumed stages per female predatory mite $( \pm \mathrm{SE})$ measured over 3 days ( $72 \mathrm{~h}$ ) and the daily mean oviposition rates ( \pm SE) based on data of day 2 and 3 (after 48 and $72 \mathrm{~h}$ ). Oviposition rates of day 1 were omitted. Different letters above bars indicate significant differences among predatory mites for that specific stage of $E$. americanus (Fisher's LSD-tests, $p<0.05)$
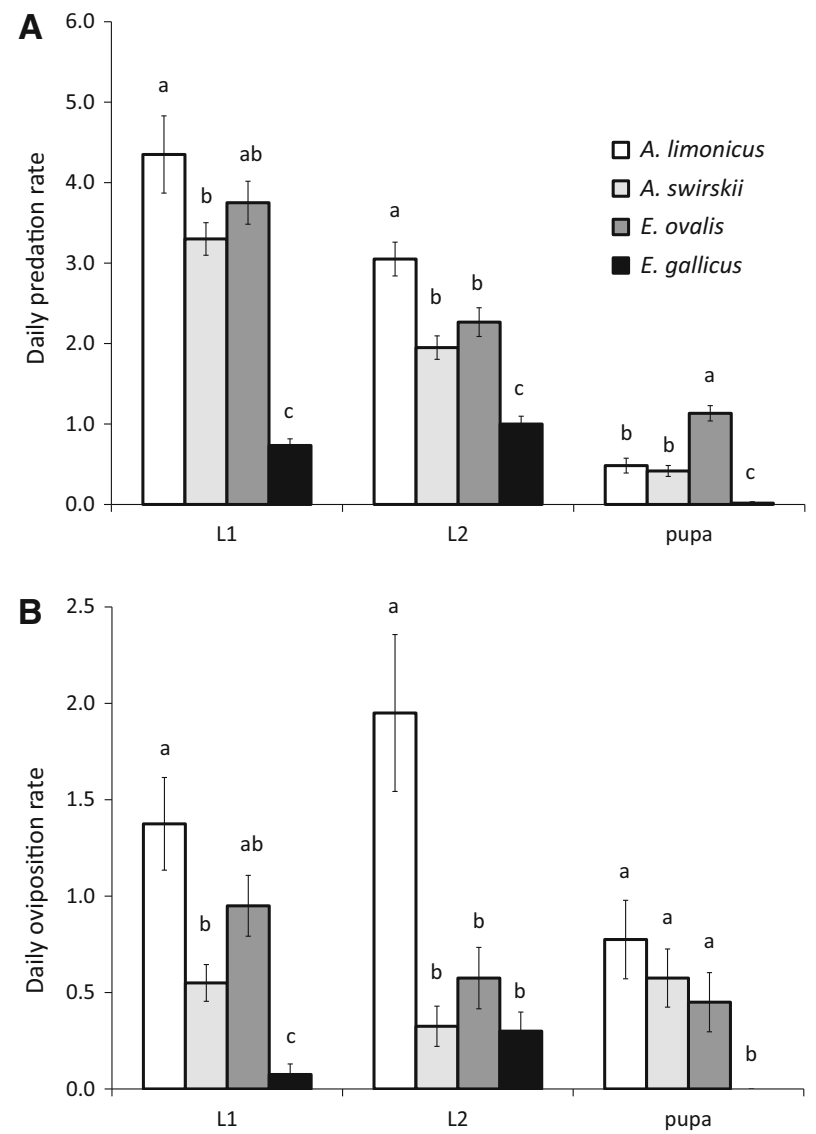
pupae (Fig. 1b). Similar to predation rates, the lowest oviposition rates were found for $E$. gallicus when first instars or pupae of thrips were provided as prey.

\section{Effects of pollen on thrips predation}

Predation of thrips was significantly lower in the presence of pollen than without pollen for both species of predatory mites $\left(\mathrm{F}_{1,21}=24.85, p<0.001\right)$, but there was no significant difference between the two predator species $\left(\mathrm{F}_{1,21}=0.76, p=0.40\right.$, Fig. 2$)$.

\section{Greenhouse trial with Amblyseius swirskii and Euseius gallicus}

There was a significant overall effect of pollen $\left(\mathrm{F}_{2,34}=4.77, p=0.039\right)$ and the factor predator (no predator, A. swirskii, E. gallicus) $\left(\mathrm{F}_{2,34}=7.63, p=0.003\right)$ on E. americanus population densities. The combination of $A$. swirskii and pollen was the only treatment resulting in lower thrips densities than the treatment without predators (Fig. 3a). The interaction effect of the factors food and predator species on predator densities was statistically significant $\left(\mathrm{F}_{2,35}=6.64, p=0.005\right)$. The densities of $A$. swirskii were significantly higher than those of E. gallicus in the absence of pollen, but in the presence of pollen densities did not differ, either with or without thrips (Fig. 3b).

\section{Greenhouse trial with Amblyseius swirskii and Euseius ovalis}

The overall effect of pollen on E. americanus populations was not significant $\left(\mathrm{F}_{2,31}=0.88, p=0.36\right)$. There was a significant effect of the factor predator (no predator, A. swirskii, E. ovalis) on E. americanus populations $\left(\mathrm{F}_{2,31}=8.57, p=0.002\right)$. Both $A$. swirskii and E. ovalis significantly reduced densities of E. americanus, but the densities among treatments with predatory mites did not differ significantly (Fig. 4a). The interaction effect of the factors food and predator species on predator densities was statistically significant $\left(\mathrm{F}_{2,35}=11.3, p<0.001\right)$. In the presence of pollen, densities of E. ovalis were more than 4 times higher than those of $A$. swirskii, but densities of the two species did not differ significantly in the absence of pollen (Fig. 4b). The presence of E. americanus did not significantly affect predator densities in the presence of pollen (Fig. 4b).

Fig. 2 Predation rates of young adult females of Euseius ovalis and Amblyseius swirskii on first larval stages of Echinothrips americanus on sweet pepper leaf discs with or without pollen pollen (Typha angustifolia). Shown are the daily mean numbers of consumed stages per female predatory mite $( \pm \mathrm{SE})$ measured over 3 days (72 h). Different letters above bars indicate significant differences among treatments (Fisher's LSDtests, $p<0.05$ )

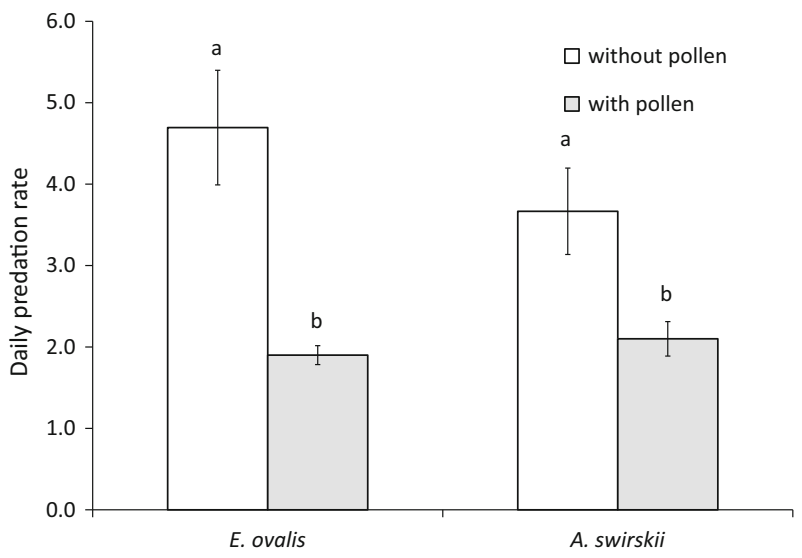



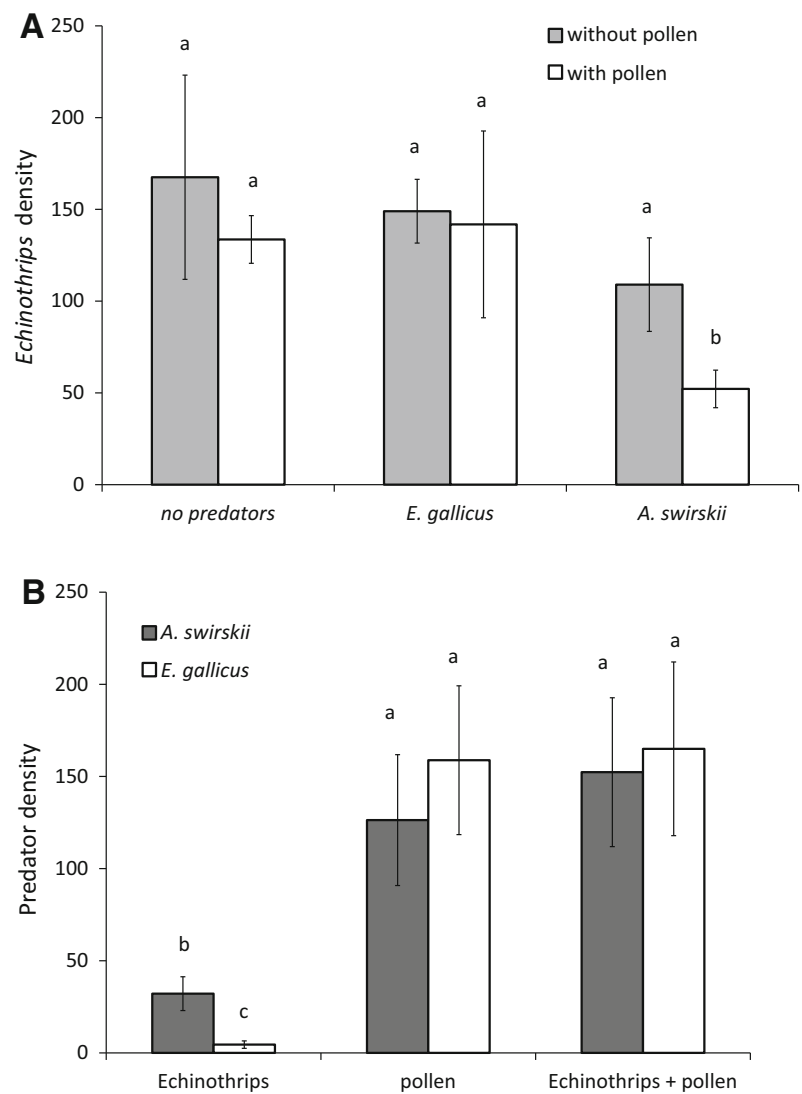

Fig. 3 Densities of Echinothrips americanus (a) and the predatory mites Amblyseius swirskii and Euseius gallicus (b) on sweet pepper plants with different treatments of the predatory mites, pollen (Typha angustifolia), thrips or combinations of these treatments. Shown are the mean densities ( \pm SE) of all stages, with the exception of the eggs, per plant. Different letters above bars indicate significant differences among treatments (Fisher's LSD-tests, $p<0.05$ )

\section{Discussion}

The results of this study show that predatory mites are potentially effective predators of the poinsettia thrips E. americanus. All species of predatory mites consumed both larval stages and pupae, although none of them preyed on adult thrips. The highest predation and oviposition rates were recorded for A. limonicus followed by A. swirskii and E. ovalis when first and second larval stages were provided as prey, but E. ovalis appeared to be the best predator of thrips pupae. E. gallicus showed very low predation and oviposition rates compared to the other species of predatory mites. The reason for this is unknown. Maybe this predator had difficulties to handle the prey, or the thrips is not a good food source for E. gallicus. The same order of efficacy for A. limonicus, A. swirskii and E. ovalis was found for the control of western flower thrips on cucumber plants (Messelink et al. 2006). Hoogerbrugge et al. (2014) also indicated that A. limonicus was more effective in controlling E. americanus on sweet pepper than A. swirskii. Particularly the relatively high oviposition rate of this predatory mite on second instar larvae of E. americanus may 
Fig. 4 Densities of Echinothrips americanus (a) and the predatory mites Amblyseius swirskii and Euseius ovalis (b) on sweet pepper plants with different treatments of the predatory mites, pollen (Typha angustifolia), thrips or combinations of these treatments. Shown are the mean densities $( \pm$ SE) of all stages, with the exception of the eggs, per plant. Different letters above bars indicate significant differences among treatments (Fisher's LSD-tests, $p<0.05$ )
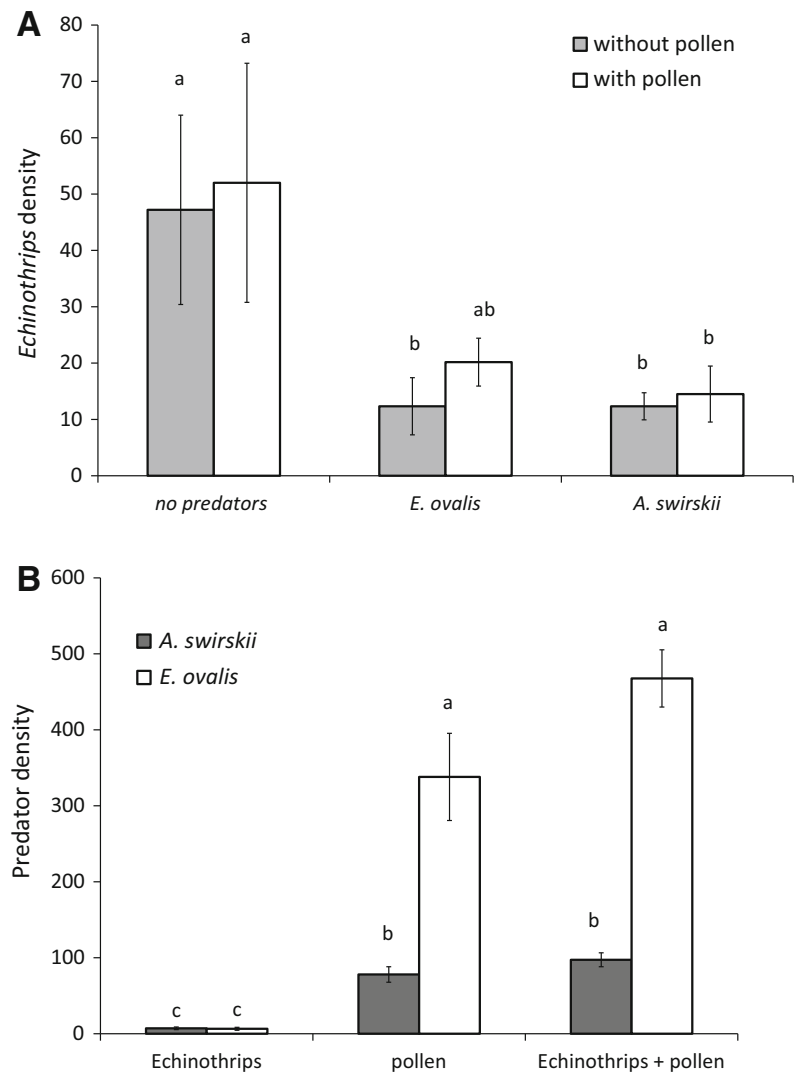

explain the efficacy of this predator. In the present study, we did not further evaluate $A$. limonicus in greenhouse experiments because we focused more of the role of pollen on the efficacy of Euseius spp., but the promising laboratory results would justify further evaluations in greenhouse trials.

The predatory mites Neoseiulus cucumeris (Oudemans) and Iphiseius degenerans (Berlese) were tested in an earlier study on sweet pepper plants, but both of them were not able to control E. americanus (Opit et al. 1997). These authors suggested that the predatory mites might not successfully attack the larger stages of E. americanus. This may be true for these species, but it is a remarkable contrast with the results of our study. The predatory mite species we tested preyed upon all immature stages of $E$. americanus. The finding that predatory mites also consume the larger stages of $E$. americanus is surprising, knowing that they mainly attack the first larval stages of tobacco thrips and western flower thrips (Bakker and Sabelis 1989; Magalhães et al. 2005). A possible explanation for the difference with E. americanus is the fact that second instars of these thrips species strongly defend themselves against predator attacks by jerking with the abdomen and producing droplets of rectal fluid (Bakker and Sabelis 1989), whereas we did not observe such strong defences in E. americanus. Bakker and Sabelis (1989) also showed that anaesthetizing the second instars of tobacco thrips increased predation rates tremendously, indicating that the defence response of thrips limited predation by predatory mites. 
Another difference with these thrips species and E. americanus is the pupation behaviour. Echinothrips americanus pupates on the plants and thus remains available as prey for leaf-dwelling predatory mites, whereas western flower thrips and tobacco thrips mainly pupate in the soil (Buitenhuis and Shipp 2008), where they can escape from predation by the leaf-dwelling predatory mites. Despite the promising results in the laboratory, the predatory mites seem to be less effective in controlling E. americanus on plants: A. swirskii and $E$. ovalis significantly reduced populations, but did not reduce the thrips to very low numbers. The reasons for these rather poor results remain unclear.

We hypothesized that pollen could enhance the control of E. americanus by predatory mites and that the effects may depend on the species of predatory mite used. Indeed, we found that cattail pollen did not allow for growth of the populations of poinsettia thrips, but it strongly increased the predatory mite densities. The densities of E. gallicus were slightly higher than those of $A$. swirskii in the presence of pollen, but $E$. ovalis densities increased to more than 4 times higher densities than A. swirskii. Compared to treatments without pollen, densities were 72 times higher. Surprisingly, these huge predator densities did not result in a significantly better control of E. americanus compared to the treatment without pollen. Thrips densities in the treatment with pollen were even slightly higher. The lack of sufficient control in the presence of very high predator densities suggest that this predator is not very effective in controlling E. americanus. The high predator densities may eventually have led to an enhanced thrips control, but our experiment did not last long enough to observe such effects. Better control may also be achieved by introducing the predators before the pests arrive and by trying to keep the predator densities with alternative food in a more or less stationary phase (Janssen and Sabelis 2015). The case for $A$. swirskii was different in the first trial: pollen clearly and significantly enhanced the control of E. americanus, but this effect was not found in the second trial. Similar to E. ovalis, the clearly higher predator densities might eventually have led to an enhanced control of $E$. americanus in the long term. The predation rates of E. ovalis on first instars of E. americanus were slightly higher than of $A$. swirskii, but this was the opposite in the presence on pollen, indicating that $E$. ovalis may have a stronger preference for pollen than A. swirskii (60 vs. $43 \%$ reduced predation respectively, Fig. 2). However, both species still consumed thrips in the presence of pollen, and the greenhouse trial also showed that pollen did not disrupt the control of E. americanus. Pollen is also suitable alternative food for $A$. limonicus (Samaras et al. 2015) and may thus be useful for enhancing the control of $E$. americanus by this predator as well. Pollen did not enhance the control of E. americanus by E. gallicus. The low predation rates of poinsettia thrips by this predator in the laboratory, were not counterbalanced by the much higher predator densities through the application of pollen. Without pollen, the predatory mites hardly survived, indicating that they also hardly attack E. americanus on plants. The predatory mite E. gallicus is relatively new (Tixier et al. 2010) and was found to occur on greenhouse rose plants (Döker et al. 2014). In this crop it is now advised to use together with pollen for controlling thrips and whiteflies because of its good performance on pollen (Pijnakker et al. 2014; Put et al. 2016). However, this study does not provide any evidence for better development on pollen on sweet pepper plants than the predatory mites A. swirskii and E. ovalis. Our data suggests that $E$. ovalis is potentially a better predator to select for establishing high predator densities based on pollen applications. However, high predator densities do not guarantee successful pest control, as shown here for E. ovalis. Particularly in the case where E. americanus is an additional pest to control besides western flower thrips and whiteflies, it may be more efficient to use A. swirskii or A. limonicus for controlling these pests than $E$. gallicus. Another strategy could be to use mixtures of predatory mite species, but intraguild 
predation among predatory mites may soon result in exclusion of some of the species (Buitenhuis et al. 2010; Montserrat et al. 2008). Summarizing, we conclude that the predatory mites A. swirskii, A. limonicus and E. ovalis are in principle good candidates for controlling E. americanus in greenhouse crops. Pollen can be used to enhance the control by $A$. swirskii, and possibly also the control by E. ovalis and A. limonicus. However, our results of the greenhouse trials were for practical reasons just based on one assessment in time and because populations show predator-prey fluctuations through time, the results of such an assessment will strongly depend on the exact time point of the assessment. Moreover, such fluctuations in time may also differ among treatments. Further experiments are therefore needed to follow populations dynamics and the level of thrips control over a longer period in order to obtain a more complete picture of the potential of these predatory mites for biological control of E. americanus.

Acknowledgements This study was funded by the Dutch Ministry of Economic Affairs and the Dutch Product Board for Horticulture. SG received a grant of the Ministry of Science, Research and Technology of Iran for visiting Wageningen UR. We thank the two anonymous reviewers for their constructive comments, which helped us to improve the manuscript.

Open Access This article is distributed under the terms of the Creative Commons Attribution 4.0 International License (http://creativecommons.org/licenses/by/4.0/), which permits unrestricted use, distribution, and reproduction in any medium, provided you give appropriate credit to the original author(s) and the source, provide a link to the Creative Commons license, and indicate if changes were made.

\section{References}

Adar E, Inbar M, Gal S, Gan-Mor S, Palevsky E (2014) Pollen on-twine for food provisioning and oviposition of predatory mites in protected crops. Biocontrol 59:307-317. https://doi.org/10.1007/ s10526-014-9563-1

Arthurs S, McKenzie CL, Chen JJ, Dogramaci M, Brennan M, Houben K, Osborne L (2009) Evaluation of Neoseiulus cucumeris and Amblyseius swirskii (Acari: Phytoseiidae) as biological control agents of chilli thrips, Scirtothrips dorsalis (Thysanoptera: Thripidae) on pepper. Biol Control 49:91-96. https:// doi.org/10.1016/j.biocontrol.2009.01.002

Bakker FM, Sabelis MW (1989) How larvae of Thrips tabaci reduce the attack success of phytoseiid predators. Entomol Exp Appl 50:47-51

Buitenhuis R, Shipp JL (2008) Influence of plant species and plant growth stage on Frankliniella occidentalis pupation behaviour in greenhouse ornamentals. J Appl Entomol 132:86-88

Buitenhuis R, Shipp L, Scott-Dupree C (2010) Intra-guild versus extra-guild prey: effect on predator fitness and preference of Amblyseius swirskii (Athias-Henriot) and Neoseiulus cucumeris (Oudemans) (Acari: Phytoseiidae). Bull Entomol Res 100:167-173. https://doi.org/10.1017/s0007485309006944

Delisle JF, Shipp L, Brodeur J (2015) Apple pollen as a supplemental food source for the control of western flower thrips by two predatory mites, Amblyseius swirskii and Neoseiulus cucumeris (Acari: Phytoseiidae), on potted chrysanthemum. Exp Appl Acarol 65:495-509. https://doi.org/10.1007/s10493-0149863-2

Döker I, Witters J, Pijnakker J, Kazak C, Tixier MS, Kreiter S (2014) Euseius gallicus Kreiter and Tixier (Acari: Phytoseiidae) is present in four more countries in Europe: Belgium, Germany, the Netherlands and Turkey. Acarologia 54:245-248. https://doi.org/10.1051/acarologia/20142132

Duarte MVA, Venzon M, Bittencourt MCD, Rodriguez-Cruz FA, Pallini A, Janssen A (2015) Alternative food promotes broad mite control on chilli pepper plants. Biocontrol 60:817-825. https://doi.org/10. 1007/s10526-015-9688-x

Gerson U, Weintraub PG (2007) Mites for the control of pests in protected cultivation. Pest Manag Sci 63:658-676. https://doi.org/10.1002/ps.1380

Heinz KM, Van Driesche RG, Parella MP (2004) Biocontrol in protected culture. Ball Publishing, Batavia Hoogerbrugge H, Lenferink KO, van Houten Y, Bolckmans K (2014) Screening of three phytoseiid mite species as biocontrol agents of Echinothrips americanus. IOBC WPRS Bull 102:97-101 
Hulshof J, Ketoja E, Vänninen I (2003) Life history characteristics of Frankliniella occidentalis on cucumber leaves with and without supplemental food. Entomol Exp Appl 108:19-32. https://doi.org/ 10.1046/j.1570-7458.2003.00061.x

Janssen A, Sabelis MW (1992) Phytoseiid life-histories, local predator-prey dynamics, and strategies for control of tetranychid mites. Exp Appl Acarol 14:233-250. https://doi.org/10.1007/bf01200566

Janssen A, Sabelis MW (2015) Alternative food and biological control by generalist predatory mites: the case of Amblyseius swirskii. Exp Appl Acarol 65:413-418. https://doi.org/10.1007/s10493-015-9901-8

Kakkar G, Kumar V, Seal DR, Liburd OE, Stansly PA (2016) Predation by Neoseiulus cucumeris and Amblyseius swirskii on Thrips palmi and Frankliniella schultzei on cucumber. Biol Control 92:85-91. https://doi.org/10.1016/j.biocontrol.2015.10.004

Knapp M, van Houten Y, Hoogerbrugge H, Bolckmans K (2013) Amblydromalus limonicus (Acari: Phytoseiidae) as a biocontrol agent: literature review and new findings. Acarologia 53:191-202. https://doi. org/10.1051/acarologia/20132088

Leman A, Messelink GJ (2015) Supplemental food that supports both predator and pest: a risk for biological control? Exp Appl Acarol 65:511-524. https://doi.org/10.1007/s10493-014-9859-y

Lewis T (1997) Thrips as crop pests. CAB International, Wallingford

Li XW, Jiang HX, Zhang XC, Shelton AM, Feng JN (2014) Post-mating interactions and their effects on fitness of female and male Echinothrips americanus (Thysanoptera: Thripidae), a new insect pest in China. PLoS ONE 9:7. https://doi.org/10.1371/journal.pone.0087725

Magalhães S, Janssen A, Montserrat M, Sabelis MW (2005) Prey attack and predators defend: counterattacking prey trigger parental care in predators. Proc R Soc Lond Ser B Biol Sci 272:1929-1933. https:// doi.org/10.1098/rspb.2005.3127

Messelink GJ, Van Steenpaal SEF, Ramakers PMJ (2006) Evaluation of phytoseiid predators for control of western flower thrips on greenhouse cucumber. Biocontrol 51:753-768. https://doi.org/10.1007/ s10526-006-9013-9

Messelink GJ, van Maanen R, van Steenpaal SEF, Janssen A (2008) Biological control of thrips and whiteflies by a shared predator: two pests are better than one. Biol Control 44:372-379. https://doi.org/ 10.1016/j.biocontrol.2007.10.017

Messelink GJ, Bennison J, Alomar O, Ingegno BL, Tavella L, Shipp L, Palevsky E, Wäckers FL (2014) Approaches to conserving natural enemy populations in greenhouse crops: current methods and future prospects. Biocontrol 59:377-393. https://doi.org/10.1007/s10526-014-9579-6

Montserrat M, Magalhaes S, Sabelis MW, de Roos AM, Janssen A (2008) Patterns of exclusion in an intraguild predator-prey system depend on initial conditions. J Anim Ecol 77:624-630. https://doi.org/ 10.1111/j.1365-2656.2008.01363.x

Mound LA (2005) Thysanoptera: diversity and interactions. Annu Rev Entomol 50:247-269. https://doi.org/ 10.1146/annurev.ento.49.061802.123318

Nomikou M, Sabelis MW, Janssen A (2010) Pollen subsidies promote whitefly control through the numerical response of predatory mites. Biocontrol 55:253-260. https://doi.org/10.1007/s10526-0099233-X

Oetting R (1987) Echinothrips americanus, a thrips of increased significance on ornamentals. In: Proceedings of the 32nd Southern Nurserymen Association Research Conference, pp 194-195

Oetting RD, Besmear RJ, Liu TX, Braman SK, Baker JR (1993) Biology and identification of thrips on greenhouse ornamentals University of Georgia. Ga Agric Exp Station Res Bull 414:1-21

Opit GP, Peterson B, Gillespie DR, Costello RA (1997) The life cycle and management of Echinothrips americanus (Thysanoptera: Thripidae). J Entomol Soc B C 94:3-6

Pijnakker J, de Souza A, Wäckers F (2014) Euseius gallicus, a bodyguard for roses. IOBC WPRS 102:191-195

Put K, Bollens T, Wackers F, Pekas A (2016) Non-target effects of commonly used plant protection products in roses on the predatory mite Euseius gallicus Kreiter and Tixier (Acari: Phytoseidae). Pest Manag Sci 72:1373-1380. https://doi.org/10.1002/ps.4162

Ramakers PMJ (1980) Biological control of Thrips tabaci (Thysanoptera: Thripidae) with Amblyseius spp. (Acari: Phytoseiidae) IOBC/wprs 3, pp 203-208

Ramakers PMJ, Van den Meiracker RAF, Mulder S (2000) Predatory thrips as thrips predators. Med Fac Landbouw Rijksuniv Gent 65:343-350

Sabelis MW (1990) How to analyze prey preference when prey density varies? A new method to discriminate between effects of gut fullness and prey type composition. Oecologia 82:289-298. https:// doi.org/10.1007/bf00317473

Sabelis MW, van Rijn PCJ (2005) When does alternative food promote biological pest control? In: Hoddle MS (ed) Proceedings of second international symposium on biological control of arthropods II, pp 428-437 
Samaras K, Pappas M, Fytas E, Broufas G (2015) Pollen suitability for the development and reproduction of Amblydromalus limonicus (Acari: Phytoseiidae). Biocontrol 60:773-782. https://doi.org/10.1007/ s10526-015-9680-5

Skirvin DJ, Kravar-Garde L, Reynolds K, Jones J, Mead A, Fenlon J (2007) Supplemental food affects thrips predation and movement of Orius laevigatus (Hemiptera: Anthocoridae) and Neoseiulus cucumeris (Acari: Phytoseiidae). Bull Entomol Res 97:309-315. https://doi.org/10.1017/S0007485307005007

Tixier MS, Kreiter S, Okassa M, Cheval B (2010) A new species of the genus Euseius Wainstein (Acari: Phytoseiidae) from France. J Nat Hist 44:241-254. https://doi.org/10.1080/00222930903383529

van Houten YM, van Rijn PCJ, Tanigoshi LK, van Stratum P, Bruin J (1995) Preselection of predatory mites to improve year-round biological control of western flower thrips in greenhouse crops. Entomol Exp Appl 74:225-234. https://doi.org/10.1111/j.1570-7458.1995.tb01895.x

van Rijn PCJ, Tanigoshi LK (1999) Pollen as food for the predatory mites Iphiseius degenerans and Neoseiulus cucumeris (Acari: Phytoseiidae): dietary range and life history. Exp Appl Acarol 23:785-802. https://doi.org/10.1023/A:1006227704122

van Rijn PCJ, van Houten YM, Sabelis MW (2002) How plants benefit from providing food to predators even when it is also edible to herbivores. Ecology 83:2664-2679

Vangansbeke D, Nguyen DT, Audenaert J, Verhoeven R, Gobin B, Tirry L, De Clercq P (2016) Supplemental food for Amblyseius swirskii in the control of thrips: feeding friend or foe? Pest Manag Sci 72:466-473. https://doi.org/10.1002/ps.4000

Varga L, Fedor PJ, Suvak M, Kiselak J, Atakan E (2010) Larval and adult food preferences of the poinsettia thrips Echinothrips americanus Morgan, 1913 (Thysanoptera: Thripidae). J Pest Sci 83:319-327. https://doi.org/10.1007/s10340-010-0301-x

Vierbergen G, Cean M, Szeller IH, Jenser G, Masten T, Simala M (2006) Spread of two thrips pests in Europe: Echinothrips americanus and Microcephalothrips abdominalis (Thysanoptera: Thripidae). Acta Phytopathol Entomol Hung 41:287-296. https://doi.org/10.1556/APhyt.41.2006.3-4.11 